\title{
Synergistic antitumour effect of recombinant human tumour necrosis factor $\alpha$ with melphalan in isolated limb perfusion in the rat
}

\author{
E. R. MAnUSAMA, P. T. G. A. NOOIJEN*, J. StAVAST, N. M. C. DURANTE, \\ R. L. MARQUET and A. M. M. EGGERMONT
}

Department of Surgery, University Hospital Rotterdam, Dr Daniel den Hoed Cancer Centre, Rotterdam and *Department of Pathology, University of Nijmegen, The Netherlands

Correspondence to: Dr E. R. Manusama, Laboratory for Experimental Surgery, Erasmus University, PO Box 1738, 3000 DR Rotterdam, The Netherlands

The efficacy of isolated limb perfusion (ILP) for 'intransit' metastases from malignant melanoma and irresectable soft tissue sarcoma has been improved considerably by the addition of tumour necrosis factor (TNF) $\alpha$. A rat sarcoma tumour model was, therefore, developed to evaluate the effects of TNF- $\alpha$, melphalan and the combination of these drugs in the treatment of sarcoma. In $\mathrm{BN}$ rats bearing the non-immunogenic BN 175 sarcoma ILPs were performed with perfusate only, TNF- $\alpha$, melphalan alone, or in combination when tumours had grown to approximately $1.5 \mathrm{~cm}$ in diameter. All rats treated with sham perfusion or perfusion with $50 \mu \mathrm{g}$ TNF$\alpha$ showed progressive disease. After perfusion with $40 \mu \mathrm{g}$ melphalan no change in tumour diameter was observed in any rats at 4 days. After a combined perfusion with $40 \mu \mathrm{g}$ melphalan and $50 \mu \mathrm{g}$ TNF- $\alpha$ complete remission was noted in 12 of 16 rats. This synergistic effect in vivo between relatively ineffective doses of TNF- $\alpha$ and melphalan was not observed in vitro.
Tumour necrosis factor (TNF) $\alpha$ in combination with interferon $\gamma$ and melphalan in isolated limb perfusion (ILP) results in a high complete remission rate in patients with 'in-transit' metastases from malignant melanoma ${ }^{1,2}$. Identical treatment has been applied to patients with irresectable soft tissue sarcoma of the limbs in an attempt to render the tumours resectable and thus avoid amputation or disarticulation. An 88 per cent overall response rate with a limb salvage rate of 87 per cent has been reported ${ }^{3}$. ILP was first described by Creech et al. ${ }^{4}$ and provides high regional drug concentrations with minimal systemic toxicity. Response rates obtained with ILP with conventional cytostatic agents, such as melphalan and doxorubicin, have been disappointing in patients with soft tissue sarcomas ${ }^{5,6}$. This prompted Liénard and co-workers ${ }^{1}$ to investigate the addition of high doses of TNF- $\alpha$ in the treatment of irresectable sarcomas.

During ILP, tumours may be exposed to extremely high levels of TNF- $\alpha$, but the disappointing results from systemic administration of TNF- $\alpha$ in phase I-II trials ${ }^{7-11}$ may be because toxicity in humans allows only for the administration of about $1 / 20-1 / 50$ of the dose required for antitumour effects in murine experimental tumour models ${ }^{12}$. As ILP can achieve a 20 -fold increase in concentration of the drug $^{13}$, this may be the best way of determining whether TNF- $\alpha$ can be used effectively.

TNF- $\alpha$ as a single agent has only been administered by ILP in a small number of patients in a feasibility study. In this study, therefore, the efficacy of TNF- $\alpha$, melphalan and the combination thereof was investigated in a rat model of ILP.

\section{Materials and methods}

Animals

Male inbred BN strain rats, weighing $250-300 \mathrm{~g}$ and obtained from Harlan-CPB (Austerlitz, The Netherlands), were used. The

Paper accepted 8 July 1995 rats were fed a standard laboratory diet (Hope Farms, Woerden, The Netherlands). They were housed under standard conditions of light and accommodation. The experimental protocols adhered to the rules outlined in the Dutch Animal Experimentation Act 1977 and the published Guidelines on the Protection of Experimental Animals by the Council of the European Community 1986. The protocol was approved by the committee on animal research of the Erasmus University, Rotterdam, The Netherlands.

\section{Tumour}

The spontaneous BN 175 sarcoma (transplantable to $\mathrm{BN}$ rats) was used ${ }^{14,15}$ and implanted subcutaneously in the flank and passaged serially. BN 175 sarcoma is a rapidly growing and metastasizing tumour. As determined by the immunization challenge method of Prehn and Main ${ }^{16}$, the BN 175 sarcoma is non-immunogenic and can be maintained in tissue culture.

\section{Melphalan}

Melphalan (Alkeran, $50 \mathrm{mg}$ per vial; Wellcome, Beckenham, UK) was diluted in $10 \mathrm{ml}$ diluent solvent. Further dilutions were made in 0.9 per cent $\mathrm{NaCl}$ to give a volume of $0.2 \mathrm{ml}$ in the perfusion circuit.

\section{Tumour necrosis factor $\alpha$}

Recombinant human TNF- $\alpha$ was provided by Boehringer (Ingelheim, Germany) with a specific activity of $5.8 \times 10^{7}$ units/ $\mathrm{mg}$ as determined in the murine L-M cell assay ${ }^{17}$. Endotoxin levels were less than 1.25 endotoxin units (EU) per $\mathrm{mg}$ protein.

\section{Tumour model}

Fragments $(3-5 \mathrm{~mm})$ of the $\mathrm{BN} 175$ sarcoma were implanted into the right hindlimb subcutaneously just above the ankle. Perfusion was performed at a tumour diameter of approximately $15 \mathrm{~mm}$ at least 7 days after implantation. Subsequent tumour growth was recorded by calliper measurement. The mean of two perpendicular diameters was obtained. Tumour diameters were measured at least three times weekly.

The classification of tumour response was: progressive disease (increase in tumour diameter more than 25 per cent within 4 days; no change (tumour diameter equal to diameter during 
perfusion (range -50 to +25 per cent)); partial remission (decrease in tumour diameter of less than -50 per cent; complete remission (no tumour palpable). When complete remission was associated with skin necrosis at the tumour site this response was classified as $\mathrm{CR}_{\mathrm{SN}}$.

\section{Isolated limb perfusion}

Modification of the perfusion technique originally described by Benckhuijsen et al. ${ }^{18}$ was used. Briefly, animals were anaesthetized with Hypnorm (Janssen Pharmaceutica, Tilburg, The Netherlands) and 50 units heparin was injected intravenously. To keep the rat's hindleg at a constant temperature of $38-39^{\circ} \mathrm{C}$, a warm water mattress was applied. The femoral artery and vein were cannulated with silastic tubing $(0.30 \mathrm{~mm}$ inner diameter, $0.64 \mathrm{~mm}$ outer diameter; $0.64 \mathrm{~mm}$ inner diameter, $1.19 \mathrm{~mm}$ outer diameter respectively; Dow Corning, Michigan, USA). Collaterals were occluded by a groin tourniquet and isolation time commenced when the tourniquet was tightened. An oxygenation reservoir and a roller pump were included in the circuit. The perfusion commenced with $5 \mathrm{ml}$ Haemaceel (Behring Pharma, Amsterdam, The Netherlands), and the haemoglobin content of the perfusate was $0.9 \mathrm{mmol} / \mathrm{l}$. Melphalan and TNF- $\alpha$ were added as boluses to the oxygenation reservoir. A roller pump (Watson Marlow, Falmouth, UK; type $505 \mathrm{U}$ ) recirculated the perfusate at a flow rate of $2.4 \mathrm{ml} / \mathrm{min}$. A washout with $2 \mathrm{ml}$ oxygenated Haemaccel was performed at the end of the perfusion. In the rat collateral circulation via the internal iliac artery to the leg is so extensive that it allows ligation of the femoral vessels without detrimental effects and, after ligation of the femoral artery, backflow from the femoral vein was seen in all rats immediately after release of the tourniquet. The partial pressure of oxygen $\left(\mathrm{P}_{\mathrm{in} r_{2}}\right)$ was similar before and after ligation of the femoral vessels ${ }^{10}$.

\section{In vivo tumour response studies}

Experiments were performed in five groups of rats; group 1, sham perfusion $(n=9)$; group 2, melphalan perfusion with total doses of $40 \mu \mathrm{g}(n=4), 0.2 \mathrm{mg}(n=6)$ and $1 \mathrm{mg}(n=4)$; group 3 , perfusion with $40 \mu \mathrm{g}$ melphalan $(n=5)$; group 4 , perfusion with $50 \mu \mathrm{g}$ ' $\Gamma \mathrm{NF}-x(n=9)$; group 5 , perfusion with $40 \mu \mathrm{g}$ melphalan and $50 \mu \mathrm{g}$ TNF- $\alpha(n=16)$. (Previous studies have shown that perfusions with even $100 \mu \mathrm{g}$ TNF- $x$ have no antitumour effects $^{14}$.)

\section{Histology}

For histopathological studies an additional 16 rats were used; four per group were sacrificed $24 \mathrm{~h}$ after treatment. Tumours were excised and fixed in 4 per cent formaldehyde solution and embedded in paraffin. Sections of the tumour were stained with haematoxylin and eosin.

\section{In vitro assessment of antitumour activity}

BN 175 sarcoma grows as a monolayer in Dulbecco's modified Eagle's medium containing 5 per cent fetal calf serum and glutamic acid $0.3 \mathrm{mmol} / \mathrm{l}$ (Gibco, Paisley, UK). The sulphorhodamine B protein stain assay was used according to the method of Skehan et al. ${ }^{24}$. Eight replicate experiments were performed. Tumour growth was calculated using the formula: tumour growth $=($ test well $/$ control $) \times 100$ per cent. The drug concentration reducing the absorbance to 50 per cent of control $\left(\mathrm{IC}_{51}\right)$ was determined from the growth curves. Sensitization ratios of combinations of melphalan with TNF-x were determined by dividing the $\mathrm{IC}_{50}$ in the presence of the single agent by the $\mathrm{IC}_{50}$ in the presence of the additional agent.

\section{Statistical analysis}

To compare tumour diameters in different animal groups the Mann-Whitney $U$ test and Student's $t$ test were used.

\section{Results}

Dose ranging for melphalan

Perfusions were performed with $1 \mathrm{mg}, 0.2 \mathrm{mg}$ and $40 \mu \mathrm{g}$ melphalan. Perfusions with $1 \mathrm{mg}$ melphalan resulted in tumour regression consisting of two of four partial remissions and two of four complete remissions. Remission was characterized by a gradual disappearance

Table 1 Antitumour effects of isolated limb perfusion in the BN 175 sarcoma model

\begin{tabular}{|c|c|c|c|c|}
\hline & $\begin{array}{l}\text { Sham } \\
\text { perfusion }\end{array}$ & $\begin{array}{l}\text { Perfusion } \\
\text { with } 50 \mu \mathrm{g} \\
\text { TNF- } \alpha\end{array}$ & $\begin{array}{l}\text { Perfusion } \\
\text { with } 40 \mu \mathrm{g} \\
\text { melphalan }\end{array}$ & $\begin{array}{l}\text { Perfusion with } \\
50 \mu \mathrm{g} \text { TNF- } \alpha \\
\text { and } 40 \mu \mathrm{g} \\
\text { melphalan }\end{array}$ \\
\hline Progressive disease & 9 & 9 & 0 & 0 \\
\hline No change & 0 & 0 & 9 & 4 \\
\hline Partial remission & 0 & 0 & 0 & 0 \\
\hline Complete remission & 0 & 0 & 0 & 3 \\
\hline $\begin{array}{l}\text { Complete remission } \\
\text { and skin necrosis }\end{array}$ & 0 & 0 & 0 & 9 \\
\hline Total & 9 & 9 & 9 & 16 \\
\hline
\end{tabular}

TNF- $\alpha$, tumour necrosis factor $\alpha$

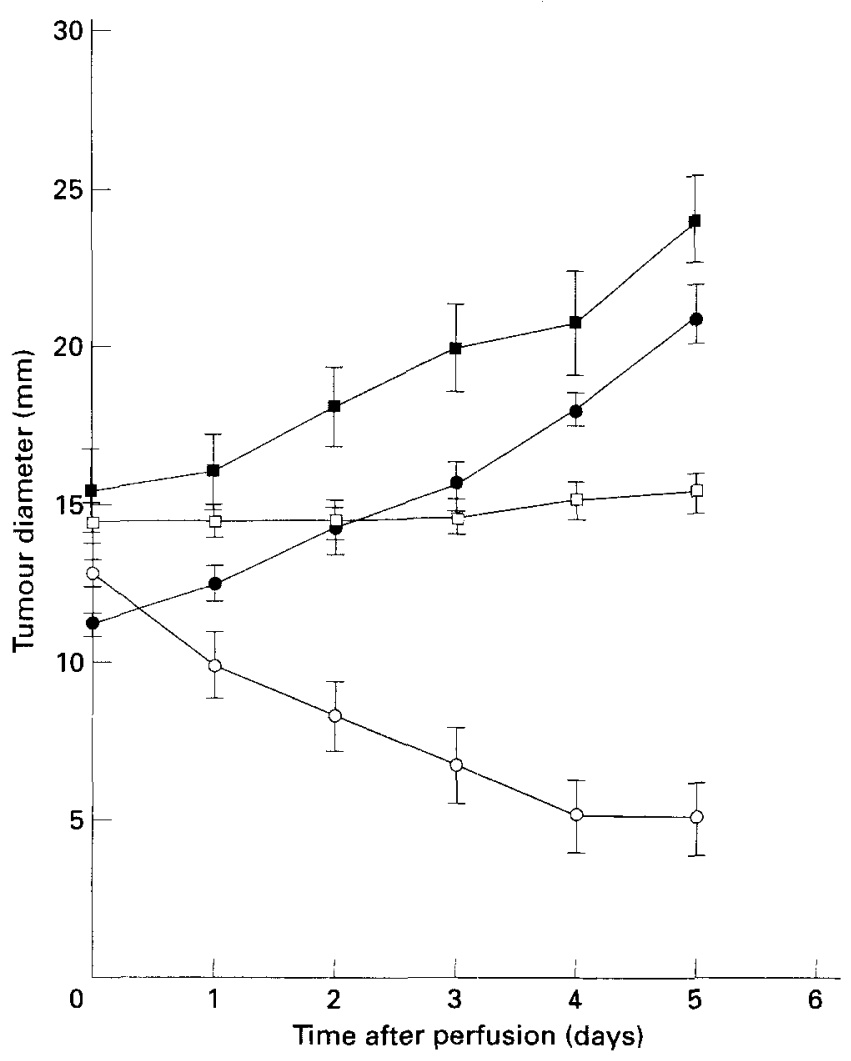

Fig. 1 Growth curves of hindlimb BN 175 sarcoma after sham

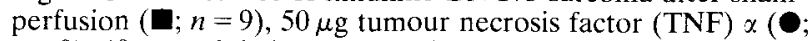
$n=9), 40 \mu \mathrm{g}$ melphalan $(\square ; n=9)$, and TNF- $x$ plus melphalan $(\mathrm{O} ; n=16)$. Values are mean(s.e.m.) of tumour diameters. At day 5 after perfusion: combined versus melphalan group, combined versus TNF- $\alpha$ group, and melphalan versus TNF- $\alpha$ group show significant differences $(P<0 \cdot 001$, Mann-Whitney $U$ test and Student's $t$ test). No significant difference was apparent between the TNF- $\alpha$ and sham groups $(P>0 \cdot 05$, Mann-Whitney $U$ test and Student's $t$ test) 
of tumour without darkening of the skin. Atrophy of the musculature occurred. In only one rat was a long-lasting complete remission obtained (sacrificed at day 105). Perfusion with $0.2 \mathrm{mg}$ melphalan resulted in no change for four of six tumours and two of six complete remissions without marked atrophic changes in the hindleg. Perfusion with $40 \mu \mathrm{g}$ melphalan inhibited tumour growth for at least 4 days in four of four rats (Table 1 ).

\section{Tumour response study}

Results are summarized in Table 1. Sham perfusion and perfusion with TNF- $\alpha$ did not inhibit tumour growth and progressive disease was observed in all rats in both groups. After perfusion with $40 \mu \mathrm{g}$ melphalan tumour growth was arrested in all five animals for at least 4 days. Complete tumour remission occurred after combined perfusion with $50 \mu \mathrm{g}$ TNF- $x$ and $40 \mu \mathrm{g}$ melphalan in 12 of 16 rats; nine of the complete remissions were classified as $\mathrm{CR}_{\mathrm{SN}}$. Recurrences were noted in eight of 16 rats. Eight rats did not have recurrences, but these rats had to be killed as they developed skin necrosis at the tumour site.

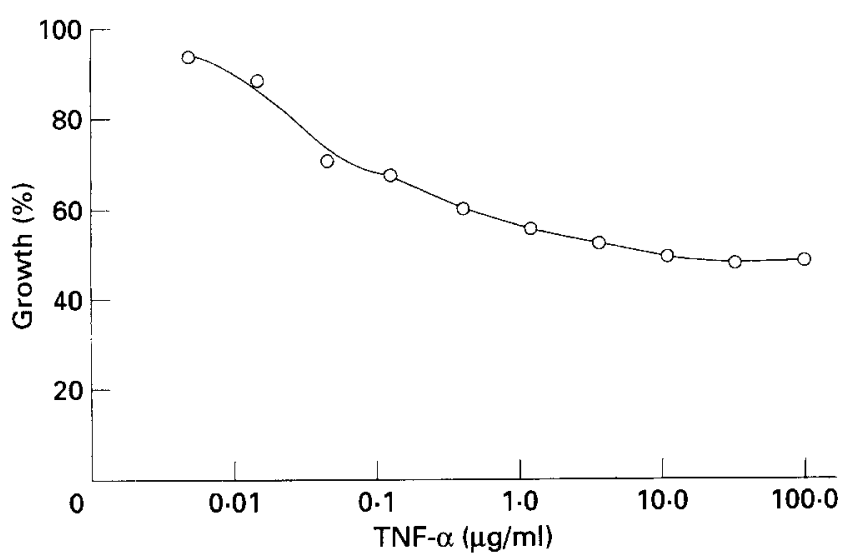

Fig. 2 Dose/response curve of BN 175 sarcoma to tumour necrosis factor (TNF) $\propto$ determined in the sulphorhodamine B assay

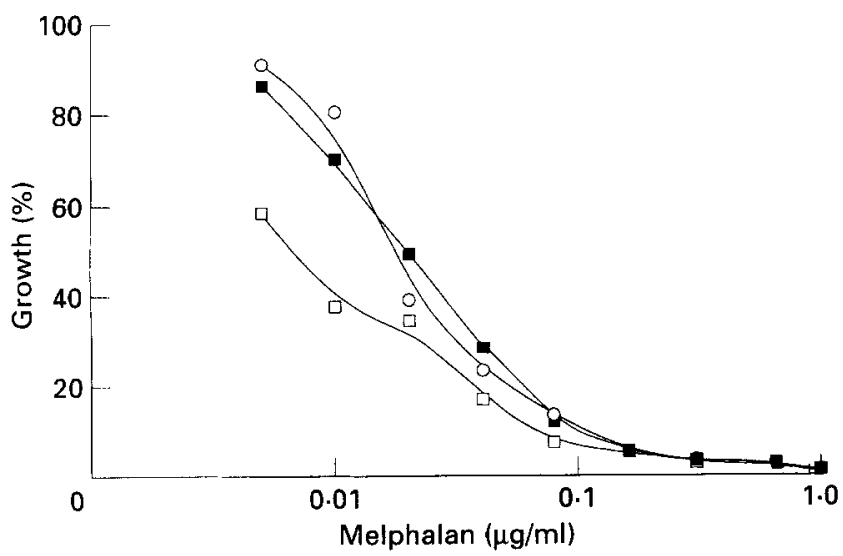

Fig. 3 Dose/response curve of BN 175 sarcoma to melphalan in the absence of tumour necrosis factor $(\mathrm{TNF}) \propto(\mathbf{0})$, in the presence of $0.1 \mu \mathrm{g} / \mathrm{ml} \mathrm{TNF-} \alpha(\bigcirc)$, and $1.0 \mu \mathrm{g} / \mathrm{ml} \mathrm{TNF-} \alpha(\square)$, determined in the sulphorhodamine B assay
Regrowth of tumour was usually seen about 11 days after perfusion (mean(s.d.) 10.9(2.8) days). In Fig. 1, growth curves of all treatment groups are shown.

\section{Histology}

In non-perfused tumours and those harvested $24 \mathrm{~h}$ after sham and melphalan ILP oedema, dilated vessels and lymphocytes, scattered through the tumour, were found. Haemorrhagic and ischaemic necrosis were absent or limited to less than 5 per cent. In addition, rats treated with TNF- $\alpha$ and the combination of melphalan and TNF- $\alpha$ demonstrated haemorrhagic necrosis in the central part of the tumour. In rats treated with TNF- $\alpha$ and melphalan haemorrhagic necrosis was much more extensive than in rats receiving ILP with $\mathrm{TNF}-\alpha$ alone. In two rats margination of polymorphonuclear cells in the tumour vessels with increased influx into the tumour was observed.

\section{In vitro cytotoxicity assay}

The in vitro dose/response curve of BN 175 sarcoma cells to TNF- $\alpha$ is depicted in Fig. 2. In Fig. 3 the dose/response curves with melphalan alone or combined with $0 \cdot 1$ and $1 \cdot 0 \mu \mathrm{g} / \mathrm{ml}$ TNF- $\alpha$ are depicted. The $\mathrm{IC}_{50} \mathrm{~s}$ were equivalent for 0 and $0 \cdot 1 \mu \mathrm{g} / \mathrm{ml} \mathrm{TNF}-\alpha$, but attenuated in the presence of $1.0 \mu \mathrm{g} / \mathrm{ml} \mathrm{TNF}-\alpha$. The mean(s.d.) sensitization ratio in the presence of $1.0 \mu \mathrm{g} / \mathrm{ml}$ TNF- $\alpha$ was $2.9(0.5)$ calculated from three different experiments. As $1.0 \mu \mathrm{g} / \mathrm{ml}$ TNF- $\alpha$ alone can reduce tumour growth to 55 per cent, the enhanced cytotoxicity is probably due to additive effects.

\section{Discussion}

These experiments have shown that TNF- $\alpha$ is only effective when administered in combination with melphalan. Isolated limb perfusion with perfusate alone or $50 \mu \mathrm{g} \mathrm{TNF}-\alpha$ alone had no impact on tumour growth and $40 \mu \mathrm{g}$ melphalan only temporarily inhibited tumour growth. In the groups perfused with the combination of both complete remission occurred in 12 of 16 rats. Histologically, haemorrhagic necrosis was observed after ILP with TNF- $\alpha$ alone but this was much more extensive with the combined treatment.

Interaction of the two agents on direct tumour cytotoxicity could be one explanation for the in vivo synergism observed. In vitro studies demonstrated no synergy, but an additive effect at best. All observations therefore indicate that the in vivo antitumour effects are mediated by indirect mechanisms such as effects on the tumour-associated vasculature (TAV); increased penetration of the cytostatic agent by these effects on TAV; and the immune system.

Disappearance of the tumour within 2-3 days together with the histological observation of haemorrhagic necrosis are typical of TNF- $\alpha$ treatment based on the vascular effects reported in many experimental studies ${ }^{21-23}$. Increased endothelial permeability, erythrostasis and thrombocyte aggregation, followed by vascular occlusion and haemorrhagic necrosis have been described in tumours treated with ILP and TNF- $\alpha$ in patients ${ }^{24}$. Moreover, preferential occlusion of all the TAV has been demonstrated angiographically in patients after ILP ${ }^{25}$. Combination of TNF- $\alpha$ with melphalan resulted in remission, which was associated with extensive 
haemorrhagic necrosis of the tumour within $24 \mathrm{~h}$ of ILP. This suggests a potentiating role of melphalan on the effects of TNF- $x$ on the TAV. For extensive haemorrhagic necrosis to occur, another detrimental agent in addition to TNF- $\alpha$ was apparently necessary. As with the alkylating agent cyclophosphamide, melphalan may well induce damage to endothelial cells ${ }^{26}$.

Better penetration of the therapeutic agents may result from increased permeability of TAV induced by TNF- $\alpha$. The synergism of specific immune therapy and cyclophosphamide in a guinea-pig metastasis model was also found to be associated with vascular leakage within tumours $^{27}$. In recent studies the accessibility of monoclonal antibodies was increased after the administration of TNF- $\alpha^{28}$. Based on these reports, melphalan delivery to the tumour may be enhanced by TNF- $\alpha$.

For sequential biopsies in patients, changes in TAV are associated with leucocyte infiltration in the tumour ${ }^{29}$. By contrast, in the present rat model increased polymorphonuclear cell margination and influx was not uniformly present in the areas of haemorrhagic necrosis. In previous studies in mice polymorphonuclear cells and macrophages have been implicated in the induction of haemorrhagic necrosis by TNF- $\alpha^{30,31}$. As distinct from their role in early $\mathrm{TNF}-\alpha$ effects such as haemorrhagic necrosis, inflammatory cells are probably of crucial importance in tumour regression in later phases ${ }^{32}$. However, this has only been shown to be the case in immunogenic and not in non-immunogenic tumours ${ }^{12}$. As a non-immunogenic tumour was used, it is likely that a second step immune reaction bllowing haemorrhagic necrosis may not be relevant in this model. In nonimmunogenic tumours, a viable rim of tumour is suggested to replace the central haemorrhagic necrosis in the tumour ${ }^{12}$. This explains the lack of tumour regression, despite haemorrhagic necrosis, found after ILP with TNF$\alpha$ alone in this model.

In conclusion, these experiments have revealed synergism between TNF- $\alpha$ and melphalan with a 75 per cent complete response rate. The model appears, therefore, to be clinically relevant. The synergy observed is mainly mediated by indirect antitumour mechanisms such as the destruction of TAV and consequently an enhanced efficacy of melphalan. Further elucidation of the mechanisms involved will be necessary to allow development of treatment programmes and to extend isolated perfusion with TNF- $\alpha$ to the treatment of other tumours such as those in the liver and lung ${ }^{33,34}$.

\section{Acknowledgements}

This work was financed in part by the Dutch Cancer Society (Grant DDHK 93-659). The authors acknowledge Boehringer Ingelheim $\mathrm{GmbH}$ for generously providing TNF- $\alpha$.

\section{References}

1 Liénard D, Ewalenko P, Delmotte JJ, Renard N, Lejeune FJ. High-dose recombinant tumor necrosis factor alpha in combination with interferon gamma and melphalan in isolation perfusion of the limbs for melanoma and sarcoma. $J$ Clin Oncol 1992; 10: 52-60.

2 Liénard D, Eggermont AM, Schraffordt Koops $\mathrm{H}$ et al. Isolated perfusion of the limb with high-dose tumour necrosis factor-alpha (TNF-alpha), interferon-gamma (IFN-gamma) and melphalan for melanoma stage III. Results of a multi- centre pilot study. Melanoma Res 1994; 4(Suppl 1): 21-6

3 Eggermont AMM, Liénard D, Schrafford Koops H, Rosenkaimer F, Lejeune FJ. Treatment of irresectable soft tissue sarcomas of the limbs by isolation perfusion with high dose TNF $\alpha$ in combination with interferon-gamma and melphalan. In: Fiers W, Buurman WA, eds. Tumor Necrosis Factor: Molecular and Cellular Biology and Clinical Relevance. Basel: Karger, 1993: 239-43.

4 Creech O Jr, Krementz ET, Ryan RF, Winblad JN. Chemotherapy of cancer: regional perfusion utilizing an extracorporeal circuit. Ann Surg 1958; 148: 616-32.

5 Krementz ET, Carter RD, Sutherland CM, Hutton I. Chemotherapy of sarcomas of the limbs by regional perfusion. Ann Surg 1977; 185: 555-64.

6 Klaase JM, Kroon BBR, Benckhuysen C, van Geel AN, Albus-Lutter ChE, Wieberlink J. Results of regional isolation perfusion with cytostatics in patients with soft tissue tumors of the extremities. Cancer 1989; 64: 616-21.

7 Spriggs DR, Sherman ML, Michie $\mathrm{H}$ et al. Recombinant human tumor necrosis factor administered as a 24-hour intravenous infusion. A phase I and pharmacologic study. $J$ Natl Cancer Inst 1988; 80: 1039-44.

8 Blick M, Sherwin SA, Rosenblum M, Gutterman J. Phase I study of recombinant human tumor necrosis factor in cancer patients. Cancer Res 1987; 47: 2986-9.

9 Chapman PB, Lester TJ, Casper ES et al. Clinical pharmacology of recombinant human tumor necrosis factor in patients with advanced cancer. $J$ Clin Oncol 1987; 5: 1942-51.

10 Feinberg B, Kurzrock R, Talpaz M, Blick M, Saks S, Gutterman JU. A phase I trial of intravenously-administered recombinant tumor necrosis factor-alpha in cancer patients. $J$ Clin Oncol 1988; 6: 1328-34.

11 Spriggs DR, Yates SW. Cancer chemotherapy. Experiences with TNF administration in humans. In: Beutler B, ed. Tumor Necrosis Factors: The Molecules and Their Emerging Role in Medicine. New York: Raven Press, 1992: 383-406.

12 Asher A, Mulé JJ, Reichert CM, Shiloni E, Rosenberg SA. Studies on the anti-tumor efficacy of systemically administered recombinant tumor necrosis factor against several murine tumors in vivo. J Immunol 1987; 138: 963-74.

13 Benckhuijsen C, Kroon BBR, van Geel AN, Wieberdink J. Regional perfusion treatment with melphalan for melanoma in a limb: an evaluation of drug kinetics. Eur J Surg Oncol 1988; 14: 157-63.

14 Marquet RL, Schellekens H, Westbroek DL, Jeekel J. Effect of treatment with interferon and cyclophosphamide on the growth of a spontaneous liposarcoma in rats. Int $J$ Cancer 1983; 31: 223-6.

15 Kort WJ, Zondervan PE, Hulsman LO, Weijma IM, Westbroek DL. Incidence of spontaneous tumors in a group of retired breeder female brown Norway rats. I Natl Cancer Inst 1984; 72: 709-13.

16 Prehn RT, Main JW. Immunity to methylcholantreneinduced sarcomas. $J$ Natl Cancer Inst 1957; 18: 769-78.

17 Kramer SM, Carver ME. Serum-free in vitro bioassay for the detection of tumor necrosis factor. J Immunol Methods 1986; 93: 201-6.

18 Benckhuijsen C, Van Dijk WJ, Van't Hoff SC. High-flow isolation perfusion of the rat hind limb in vivo. J Surg Oncol 1982; 21: 249-57.

19 Manusama ER, Durante NMC, Marquet RL, Eggermont AMM. Ischemia promotes the antitumor effect of tumor necrosis factor alpha (TNF $\alpha)$ in isolated limb perfusion in the rat. Reg Cancer Treat 1994; 7: 155-9.

20 Skehan P, Storeng R, Scudiero D et al. New colorimetric cytotoxicity assay for anticancer-drug screening. $J$ Natl Cancer Inst 1990; 82: 1107-12.

21 Watanabe N, Niitsu Y, Umeno $\mathbf{H}$ et al. Toxic effect of tumor necrosis factor on tumor vasculature in mice. Cancer Res 1988; 48: 2179-83.

22 Bloksma N, van de Wiel PA, Kuper CF, Hofhuis FMA. Multiple facets of induction of tumour necrosis. Annales de L'institut Pasteur-Immunologie 1988; 139: 294-9. 
23 Nawroth P, Handley D, Matsueda G et al. Tumor necrosis factor/cachectin-induced intravascular fibrin formation in meth A fibrosarcomas. J Exp Med 1988; 168: 637-47.

24 Renard N, Nooijen P, Schalkwijk L et al. VWF release and platelet aggregation in human melanoma after perfusion with TNF alpha. J Pathol 1995; 176: 279-87.

25 Eggermont AMM, Schraffordt Koops H, Lienard D, Lejeune FJ, Oudkerk M. Destruction of tumor associated vessels by isolated limb perfusion with tumor necrosis factor- $x$ : angiographic observations in sarcoma patients. Eur J Surg Oncol 1994; 20: 403 (Abstract).

26 Kachel DL, Martin WJ II. Cyclophosphamide-induced lung toxicity: mechanism of endothelial cell injury. $J$ Pharmacol Exp Ther 1994; 268: 42-6.

27 Key ME, Brandhorst JS, Hanna MG Jr. Synergistic effects of active therapy and specific immunotherapy and chemotherapy in guinea pigs with disseminated cancer. J Immunol 1983; 130: 2987-92.

28 Folli S, Pelegrin A, Chalandon Y et al. Tumor-necrosis factor can enhance radio-antibody uptake in human colon carcinoma xenografts by increasing vascular permeability. Int J Cancer 1993; 53: 829-36.

29 Renard N, Liénard D, Lespagnard L, Eggermont A, Heimann R, Lejeune F. Early endothelium activation and polymorphonuclear cell invasion precede specific necrosis of human melanoma and sarcoma treated by intravascular highdose tumour necrosis factor alpha (rTNF $\alpha$ ). Int $J$ Cancer 1994; 57: 656-63.

30 al Attiyah RA, Rosen H, Rook GAW. A model for the investigation of factors influencing haemorrhagic necrosis mediated by tumour necrosis factor in tissue sites primed with mycobacterial antigen preparations. Clin Exp Immunol 1992; 88: 537-42.

31 Yi ES, Ulich TR. Endotoxin, interleukin-1, and tumor necrosis factor cause neutrophil-dependent microvascular leakage in postcapillary venules. Am J Pathol 1992; 140: 659-63.

32 Asher AL, Mule JJ, Rosenberg SA. Recombinant human tumor necrosis factor mediates regression of a murine sarcoma in vivo via Lyt-2 ${ }^{+}$cells. Cancer Immunol Immunother 1989; 28: 153-6.

33 Weksler B, Blumberg D, Lenert JT, Ng B, Fong Y, Burt ME. Isolated single-lung perfusion with $\mathrm{TNF}-\alpha$ in a rat sarcoma lung metastases model. Ann Thorac Surg 1994; 58: 328-32.

34 Progrebniak HW, Witt CJ, Terrill R et al. Isolated lung perfusion with tumor necrosis factor: a swine model in preparation of human trials. Ann Thorac Surg 1994; 57: 1477-83. 